ORIGINAL ARTICLE

\title{
Productivity losses from injury in China
}

\author{
Y Zhou, T D Baker, K Rao, G Li
}

Injury Prevention 2003;9:124-127

See end of article for authors' affiliations

Correspondence to:

Professor Timothy D Baker,

Johns Hopkins University

Bloomberg School of Public

Health, $615 \mathrm{~N}$ Wolfe

Street, Baltimore, MD

21205, USA;

tbaker@jhsph.edu

\begin{abstract}
Objective: To examine the productivity losses and costs of injury and disease in China using an improved approach.

Methods: Potentially productive years of life lost (PPYLL) were calculated for injury and four major disease groups (respiratory, cardiovascular, infectious, neoplastic).

Data sources: The mortality data are from the 1999 National Health Statistics Report and the morbidity data from the 1998 Second National Health Service Survey Report.

Results: Injuries caused an annual PPYLL of 12.6 million years, more than for any disease group. The estimated annual economic cost of injury is equivalent to US $\$ 12.5$ billion, almost four times the total public health services budget of China. Motor vehicle fatalities accounted for $25 \%$ of the total PPYLL from all injury deaths.

Conclusion: Injury control and prevention programs merit priority to reflect the social and economic burden of injury in China.
\end{abstract}

listis njury has emerged as an important public health problem in China. ${ }^{12}$ According to China's National Center for Health Information and Statistics, ${ }^{3}$ injury is the leading cause of death for children and adults ages 1 to 44 years and the fifth leading cause of death overall. With motor vehicle production tripling in the past decade, motor vehicle crashes have become the number one cause of injury mortality in China, followed by suicide and drowning. ${ }^{4}$ It is estimated that each year in China, injury claims about 750000 lives and results in 3.5 million hospitalizations. ${ }^{3}$ Despite the importance of injury as a public health problem in China, little resource has been deployed to support injury prevention and control programs.

The concept of potentially productive years of life lost (PPYLL) is based on the productive value of individuals. The history of estimating human capital, the value of human life, goes back for centuries. One of the first references is in the Bible, book of Leviticus (chapter 27, verses 3-7), which sets the value of men and women of working age, children, and the elderly at different levels. Key references from the past include Political Arithmetick by Sir William Petty, ${ }^{5}$ The Money Value of a Man by Louis Dublin, ${ }^{6}$ and Estimating the Cost of Illness by Dorothy Rice.?

In 1982, the US Centers for Disease Control introduced the concept of years of potential life lost (YPLL) (0-64). ${ }^{8}$ YPLL has been used by the Pan American Health Organization ${ }^{9}$ and in several studies in China. ${ }^{10-15}$ The World Health Organization has developed a complex method for estimating disability adjusted years of life lost, or DALYs, based in part on the assumption that everyone should have the life expectancy of Japanese females. ${ }^{16}$ The appropriateness of using quality adjusted life years (QALYs) for resource allocation, however, has been questioned. ${ }^{17}$ While DALYs measure the potential impact of a health problem on the quality of life of individuals, PPYLL provides more relevant information about the effect of a medical condition on the economy.

Using data recently available from the Ministry of Health and an improved technique PPYLL to measure the economic burden of health problems, this study compares the PPYLL from injuries with four major disease groups.

The measure, PPYLL (age 15-64), underscores the importance of productivity as a vital part of a country's development. We choose this method in preference to DALYs, which include the years lost well beyond the productive years. ${ }^{16}$

Setting priorities for health expenditure for disease control programs should reflect the economic costs (direct and indirect) of the disease. It should also reflect the different costs of competing health programs. This article deals only with the productivity loss of injury and illness. We hope that the results of this study will lead to a more balanced health agenda in China, with adequate investment in research, training, and intervention programs aimed at reducing the mortality and morbidity from injuries.

\section{METHODS}

\section{Sources of data}

Data came from current Chinese language sources. The 1999 mortality data by age, sex, rural/urban location, and cause (injury and major disease groups) came from China's National Center for Health Information and Statistics, Ministry of Public Health. ${ }^{3}$ This source is based on a geographically representative sample of 36 cities and 85 rural counties. The urban sample included large cities with more than one million nonagricultural population, as well as medium and small cities with less than 300000 non-agricultural population. The rural sample consisted of counties at various levels of economic development.

Morbidity data came from the 1998 report of the Second National Health Services Survey, which was based on a representative sample of 210000 individuals from 57000 households in $1997 .{ }^{18}$ Self reported work days lost in the previous two weeks from cause specific acute morbidity were used in computing morbidity-attributed PPYLL.

Estimates of the 0-64 population were based on the latest (1996) population projection in the United Nations Demographic Yearbook. ${ }^{19}$ We expanded the final 1996 population by $3 \%$ to reflect the increase of population from 1996 to $1999 .^{20}$

Mortality data from the earlier years' World Health Organization Statistics Annuals were used to calculate PPYLL by age, gender, rural/urban location, and cause in 1987 and 1992 to show time trends. ${ }^{21} 22$

Direct costs of injury data came from the Second National Health Services Survey. Data for average annual earnings came from China Statistics Yearbook..$^{23}$

Abbreviations: DALYs, disability adjusted years of life lost; PPYLL, potentially productive years of life lost; QALYs, quality adjusted life years; YPLL, years of potential life lost 


\begin{tabular}{lll}
$\begin{array}{l}\text { Table } 1 \\
\text { group }\end{array}$ & Discounted productive years lost by age \\
\hline Age group & PPYLL & Discounted PPYLL \\
\hline 0 & 50 & 17 \\
$1 \sim 4$ & 50 & 17 \\
$5 \sim 14$ & 50 & 22 \\
$15 \sim 24$ & 45 & 25 \\
$25 \sim 34$ & 35 & 22 \\
$35 \sim 44$ & 25 & 18 \\
$45 \sim 54$ & 15 & 12 \\
$55 \sim 64$ & 5 & 4.6 \\
\hline
\end{tabular}

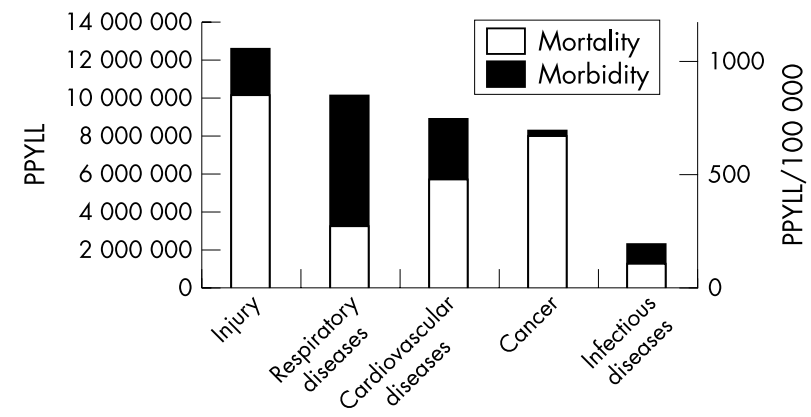

Figure 1 PPYLL from mortality and morbidity, injury and major disease groups, China, 1999.

\section{Analysis}

The PPYLL method assumes that productive ages are from age 15-64. (The working age span can be changed if it is inappropriate for a given country.) For deaths before age 15, it is assumed that if the children had survived, they would have worked the full 50 years (15-64). The loss of potentially productive years of life for children is discounted back to the midpoint of their age group. PPYLL does not take into account the factor of competing causes of death.

Recognizing the economic principle that years in the future are worth less than years in the present, the PPYLL method applies a 3\% discount rate, compounded, for years of life in the future lost to premature death. The World Bank and World Health Organization also use a $3 \%$ discount rate. ${ }^{24}$ The method calculates future years lost from deaths in each 10 year age group from the midpoint of that period. Rather than giving a formula, an example is more easily understood. For example, deaths in the 15-24 year age group would result in an average of 45 lost years of productive work. Discounted by a compounded annual 3\%, this would be about 25 years lost. Deaths in the 55-65 years age group would result in an average loss of 5 years (discounted $=4.6$ years). Table 1 gives the discounted years of productivity loss by age groups. The total loss of productive years is the sum of all age groups. We expanded the years lost from the sample of deaths to years lost by the total Chinese population of 1999 by multiplying the age specific mortality rates of the sample by the total population of each 10 year age group from $0-64$ years.

In addition to the years of life lost in the future from premature mortality, there are current morbidity losses. Losses of current productivity were based on the days of work lost per 1000 population from injury or disease applied to the total working-age population of China. To convert days lost to years lost, we divided the days lost by 260 , the estimated work days per year. We calculated PPYLL separately for injury and four other disease groups.

To estimate the losses due to different types of injury (falls, drowning, etc), we used only premature mortality, because morbidity data by type of injury were not available.

To measure the economic impact of injury we used direct costs (physician fees, hospitalizations, medicine, etc) reported in the Second National Health Services Survey. We multiplied the average expenditure per ambulatory visit by the annual ambulatory visits to obtain the direct cost of ambulatory care by injury and disease groups. Direct costs of hospitalizations were calculated by multiplying the average expenditure per hospitalization by the annual number of hospitalizations.

Indirect costs were calculated by multiplying the average per capita earnings by the years of productivity lost from morbidity and premature mortality every year. According to China's official statistics, rural average earning per capita was approximately 600 US dollars, and urban average earning per capita was 1000 US dollars in 1999. ${ }^{23}$

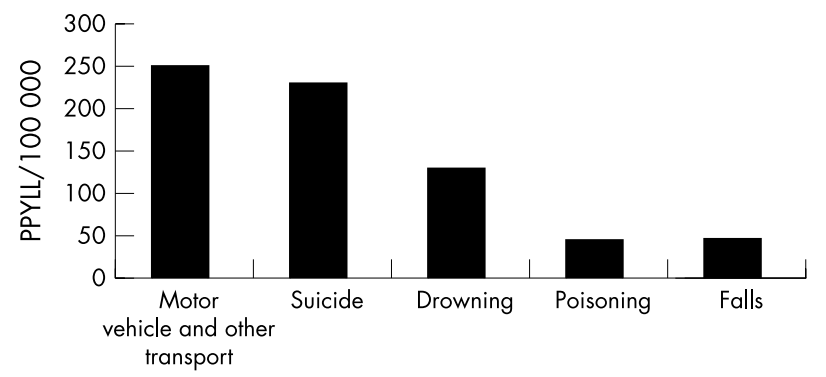

Figure 2 PPYLL from mortality by type of injury, China, 1999.

\section{RESULTS}

\section{Injury versus disease}

Injuries caused an annual 12.6 million years of lost productivity, followed by respiratory diseases (10.2 million years), cardiovascular diseases ( 9.0 million years), cancer ( 8.3 million years), and infectious diseases (2.3 million years). The rates of PPYLL/100 000 are shown in fig 1 to permit comparison with other countries.

Of injury-attributed PPYLL, $80 \%$ was due to premature mortality, $20 \%$ due to morbidity. In contrast, $70 \%$ of respiratory disease-attributed PPYLL was due to morbidity (fig $1)$.

\section{Type of injury}

Analysis of PPYLL from premature death by type of injury showed that traffic related injuries were the major source of lost productivity due to injury (fig 2). In 1999, traffic related injury deaths resulted in 250 PPYLL/100 000 population, followed by suicide (230 PPYLL/100 000), drowning (130 PPYLL/100 000), poisoning (45 PPYLL/100 000), and falls (45 PPYLL/100 000). Together, these types of injuries accounted for $80 \%$ of all injury death-attributed PPYLL. Motor vehicle crashes caused $25 \%$ of total productive years lost from all injuries.

\section{Time trends, rural/urban, and gender differences}

Rates of PPYLL/100 000 population permitted comparisons of gender, temporal, and rural/urban differences. PPYLL/100 000 lost from motor vehicle crashes and other transport injury increased from 1987 to 1999 (fig 3). Rural populations had a greater increase $(80 \%)$ as well as higher PPYLL rates initially. As expected, male rates were higher than female rates for essentially all ages and all causes of injury (fig 3).

Figure 4 displays divergent age specific death rate patterns, with drowning primarily affecting children and motor vehicle injury primarily affecting young adults.

\section{Cost of injury}

The total annual cost of injury among 0-64 age groups was calculated to be US\$12.5 billion in 1999. Of the total cost, 


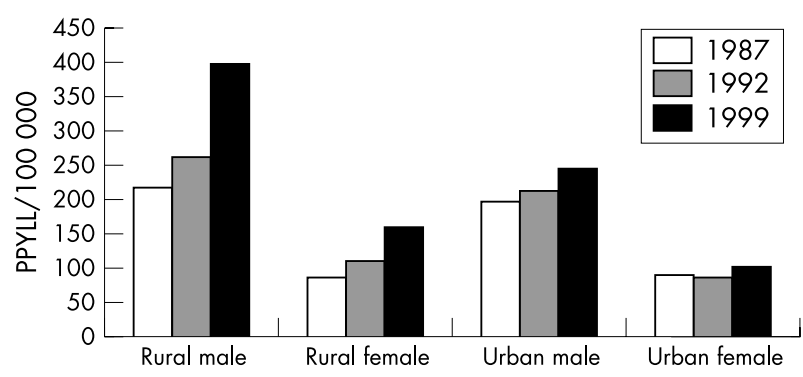

Figure 3 PPYLL from mortality, motor vehicle and other transport, China 1987, 1992, 1999.

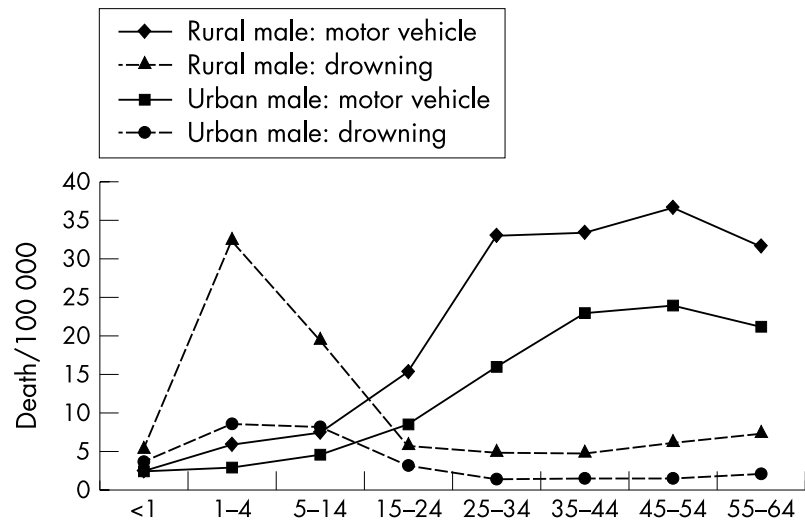

Figure 4 Age specific death rate, China, 1999; motor vehicle and other transport and drowning.

about US $\$ 3.5$ billion was direct costs for ambulatory and hospitalization care and US\$9 billion was indirect economic losses from morbidity and premature mortality.

\section{DISCUSSION}

The PPYLL technique, simple in concept, can be modified to suit different countries, and has the advantage of estimating productivity losses. In developing, industrializing countries such as China, it is essential to measure disease and injury losses for the productive working population. Decision makers with interests in increasing the nation's productivity should find the information persuasive.

The most significant result of our analysis is that PPYLL from injury outweighed the losses due to respiratory diseases, cardiovascular diseases, cancer, or infectious diseases. The ranking is not universal, but may be typical of most countries with rapid economic development ${ }^{25}$ as well as industrialized countries.

According to the World Health Organization's estimation using the DALYs approach based on less complete mortality and morbidity data, injury caused 37 million years lost in China, cardiovascular diseases 23 million years lost, respiratory diseases 22 million years lost, cancer 18 million years lost, and infectious diseases 16 million years lost, ${ }^{16}$ which are generally consistent with our results.

To place the importance of the injury problem in perspective, a comparison is useful. The annual PPYLL from injury ( 12.6 million years) equals the loss of 12.6 million laborers in one year. This is more than the total number of new entrants to the labor force each year (9.7 million). ${ }^{26}$ The cost of injury (US $\$ 12.5$ billion) was almost four times the total government spending on all public health services (US\$3.4 billion) in 1998..$^{20}$

One limitation of this study is that the mortality, morbidity, and direct costs are drawn from a large, presumably representative sample. But given the tremendous geographic and

\section{Key points}

- Injury causes more productivity losses than any disease group in China.

- Productivity losses from injury more than offset the total productivity of new entrants to the labor force each year.

- Annual economic costs of injury are more than three times the total government public health expenditure.

- Motor vehicle crashes, suicide, drowning, poisoning, and falls account for $80 \%$ of the productivity losses from injury mortality.

- Injury control and prevention merits high priority in China's health agenda.

socioeconomic diversity in China, sampling bias may be inevitable. Due to the lack of detailed disability data by injury and disease groups, we were not able to calculate the PPYLL, direct and indirect costs caused by disability. Therefore, the productivity and economic loss of injury and other disease groups are somewhat under-estimated.

The findings have major implications for relevant government agencies and international organizations such as the World Bank and the World Health Organization. The opportunity for enhanced productivity should give priority for appropriate injury prevention programs. The divergent age patterns of different types of injury indicate that injury control programs should be age appropriate. For instance, drowning prevention should target children and traffic safety programs should emphasize adults.

The excessive PPYLL from motor vehicle crashes in rural areas will worsen the already lower rural health status and hinder economic development in rural areas. Further research is needed to identify risk factors for traffic related injuries among rural residents. It is unclear how much the hazardous road conditions and poorly maintained vehicles have contributed to the high PPYLL rates in rural areas. Farmers who emigrate to cities for seasonal jobs may also be exposed to heightened risk of injury when navigating the often chaotic, unfriendly traffic and unfamiliar road environment of the urban areas.

Research is also needed to develop cost effective intervention programs. Although the magnitude of the injury problem is increasingly recognized by health authorities in China, little research has been done there on injury prevention programs such as use of seatbelts by motor vehicle occupants, and safety helmets by bicyclists, motorcyclists, and moped riders. These programs have been implemented in many developed and some less developed countries and have proved effective.

China started a national poison control center in 2000 to provide technical support for treating poisoning cases. The newly established Chinese Center for Disease Control should consider establishing a center devoted to the control and prevention of injuries. One of the injury control and prevention center's responsibilities should be to coordinate the health sector and other sectors in formulating and implementing strategic plans for reducing the tremendous burden of injury.

\section{Authors' affiliations}

Y Zhou, T D Baker, Department of International Health, Johns Hopkins University Bloomberg School of Public Health

K Rao, China National Center for Health Information and Statistics,

Ministry of Health of China

G Li, Emergency Medicine, Johns Hopkins University School of Medicine

\section{REFERENCES}

1 Li GH, Baker SP. A comparison of injury death rates in China and the United States, 1986. Am J Public Health 1991;81:605-9.

2 Roberts I. Letter from Chengdu: China takes to the roads. BM 1995;310:311-3. 
3 Ministry of Health, People's Republic of China. 1999 China National Health Statistics. Beiiing: The Ministry, 2000.

4 Wards Communications. Ward's motor vehicle facts and figures. Southfield, MI: Wards Communications, 1999

5 Sir William Petty. Political arithmetick, or a disease concerning the extent and value of lands people buildings etc. London: Printed for Richard Cleavel, 1699

6 Dublin, LI, Lotka AJ. The money value of a man. New York: Ronald Press, 1946.

7 Rice DP. Estimating the cost of illness. PHS Publication No 947-6. Washington, DC: USGPO, 1966.

8 Centers for Disease Control. Introduction to table V. Premature deaths, maternal mortality etc, United States. 1982;31:109-10, 17

9 Pan American Health Organization. Health conditions in the Americas. Volume 1. Scientific Publication No 500. Washington, DC: PAHO, 1986: 369-90.

10 Chi GB, Wang SY. A comparative study on mortality and YPLL of accidents. Chinese Journal of Epidemiology 1996;17:195-8

11 Yang GH, Huang ZJ, Tan J, et al. Priorities of disease control in China-analysis on mortality data of National Disease Surveillance Points System. Chinese Journal of Epidemiology 1996;17:199-202.

12 Zhao J, Zhang KZ, Mei JM, et al. An Analysis on the death causes and the YPLL of the population in Jiangxi Province Disease Surveillance Point System (DSP) from 1997 to 1998. China Public Health 2001;17:178-9.

13 Chen SW, Qi GY. Analysis on the Accidental Injury Death in PiZhou City during 1990 1999. China Public Health 2001;17:180.

14 Di XJ, Liu GH, Shen ZY, et al. Analysis of mortality data from 1998 Disease Surveillance Point System (DPS) in He Nan Province. China Public Health 2001;17:250.
15 Shen ZY, Ma GF, Di XJ, et al. An analysis on the death causes and the YPLL of the population in He Nan Province Disease Surveillance Point System (DSP) from 1995 to 1999. China Public Health $2001 ; 17: 555-7$.

16 Murray CJL, Lopez AD. The global burden of disease. Cambridge, MA: Harvard University Press, 1996: 553-6.

17 Burrows C, Brown K. QALYs for resource allocation: probably not and certainly not now. Aust J Public Health 1993;7:278-86.

18 Ministry of Health, People's Republic of China. Research on National Health Services - an analysis report of the Second National Health Services Survey in 1998. Beijing: National Center for Health Information and Statistics, 1999.

19 United Nations. Demographic yearbook, 1998. New York: United Nations Publication, 2000: 173-4.

20 Ministry of Health, People's Republic of China. China health statistics yearbook 2000. Beijing: China Medical Publishing House, 2000.

21 World Health Organization. World health statistics annual 1989. Geneva: WHO, 1989: 368-75.

22 World Health Organization. World health statistics annual 1994 Geneva: WHO, 1994: 322-9.

23 National Bureau of Statistics of China. China statistics yearbook 2000. Beijing: China Statistics Press, 2001.

24 World Bank. World development report 1993: invest in health. New York: Oxford University Press, 1993: 26.

25 Ketcham K, Baker T. Burden of motor vehicle injuries in Latin America Measuring the burden of Injury. 3rd International conference proceedings. Baltimore, 16 May 2000.

26 World Bank. World development report 2000/2001. New York: Oxford University Press, 2000: 278.

- Agenda for quality: Improving equity in health care delivery

- Improving safety

- Leadership for improvement

- Measuring quality and benchmarking for change

- Evidence based knowledge and education for quality improvement

- Improving health systems

- Patient/consumer centred quality improvement

Presented to you by the BM Publishing Group (London, UK) and Institute for Healthcare Improvement (Boston, USA), supported by the New Zealand Ministry of Health, ACC, and Standards New Zealand.

For more information about the Forum or to register contact: quality@bma.org.uk or go to:

www.quality.bmipg.com

Tel: +44 (0)2073836409 Fax: +44 (0)2073836869 